Received Date : 13-Jan-2016

Revised Date : 11-May-2016

Accepted Date : 17-May-2016

Article type : Our Experience

\title{
Current practice in septal surgery and adjunctive turbinate reduction - A multi-site experience in 226 consecutive cases
}

\section{Authorship}

Miss Alison Carter

ENT Surgical Registrar

Royal National Throat Nose and Ear Hospital

Dr Richard Jackson

Foundation Year Two Doctor

James Paget University Hospital

Mr Carl Philpott

Consultant ENT Surgeon

James Paget University Hospital

Miss Claire Hopkins

Consultant ENT Surgeon

This article has been accepted for publication and undergone full peer review but has not been through the copyediting, typesetting, pagination and proofreading process, which may lead to differences between this version and the Version of Record. Please cite this article as doi: 10.1111/coa.12680

This article is protected by copyright. All rights reserved. 


\section{Conflicts of Interest}

Miss Claire Hopkins and Mr Carl Philpott have jointly submitted a bid for the 'Septoplasty for a deviated nasal septum' National Institute for Health Research (NIHR) randomised control trial

Dear Editor,

Septal and turbinate surgeries are often performed concurrently for nasal obstruction, yet the causative pathology for each structure becoming symptomatic can usually be attributed to structural deformity and mucosal problems respectively. It should therefore follow that the decision to perform septoplasty, turbinate reduction, or both procedures simultaneously should be at an individual patient level according to the relevant pathology.

Septal surgery is most commonly performed for nasal obstruction due to a structural deformity, which can be either congenital, or acquired secondary to trauma. Septal deviation is common, with 79\% of adults (1) not having a straight septum. Further subdivision into physiological and pathological septal deviations can be made, as only some patients will subjectively report a reduction of nasal breathing. Less common indications for septal surgery include functional endoscopic sinus surgery access, lacrimal gland surgery, nasal and sinus tumours, pituitary surgery, to enable continuous positive airway pressure (CPAP) usage, recurrent epistaxis, and , controversially, the treatment of contact headaches (Sluder's neuralgia).

Turbinate surgery is most commonly performed for nasal obstruction due to turbinate hypertrophy, which impedes nasal airflow. Hypertrophy can be due to either an enlargement of the mucosal or osseous component of the turbinate (2). Mucosal enlargement is usually bilateral and is a secondary result to rhinitis, the aetiology of which can be allergic, infective, vasomotor, or secondary to medication. Treatment is therefore usually medical with steroid and antihistamine topical sprays or systemic medication. Surgery can be beneficial in cases which are refractory to medical treatment due to irreversible fibrosis and varicosed submucosal venous sinuses.

Osseous enlargement is usually unilateral and is linked with septal deviation. It has been hypothesised that the concave inferior turbinate enlarges to protect the larger nasal cavity from increased airflow and subsequent drying, but there are other theories of the larger inferior turbinate pressing on the septal cartilage and causing a subsequent deviation (3).

There is little consensus on the most effective surgery for turbinate reduction, and therefore many methods exist (4). Methods used include submucosal diathermy, radical turbinectomy, partial turbinectomy, outfracturing, cryotherapy, laser reduction, radiofrequency reduction and

This article is protected by copyright. All rights reserved. 
powered turbinate reduction. It was observed that trends of surgical technique appeared to be more driven by technology rather than based on compelling evidence (5).

We reviewed our experience across two hospital sites of 226 consecutive septoplasty cases to better understand the decision making within our ENT departments, and to review if there were any cross-site differences.

\section{Methods}

\section{Ethical consideration}

Data was collected at two sites: Guy's Hospital, London (GH), and the James Paget University Hospital, Norfolk (JPUH), as an audit of practice, acceptable under both hospitals' research and development guidelines. Electronic theatre record systems were searched using the septoplasty code E036. Those undergoing septoplasty for access as part of endoscopic sinus surgery (ESS) were excluded. Records of identified patients were hand searched to retrospectively collect data. Operating surgeon, grade of surgeon, method of turbinate reduction, and whether previous RAST or skin-prick testing had been performed was recorded. The presence of asthma was also recorded for those patients at Guy's Hospital.

\section{Results}

At Guy's Hospital, 201 patients were identified in the 6-month period between $19^{\text {th }}$ July 2014 $19^{\text {th }}$ January 2015. Sixteen patients were excluded for incorrect coding (8.6\%), where ESS had been performed in the absence of septal surgery. The final number of patients identified to have undergone septoplasty was 185 . Adjunctive turbinate surgery was performed in $74.1 \%$ of patients. At the James Paget University Hospital, 26 patients were identified in the 6-month period between $19^{\text {th }}$ July $2014-19^{\text {th }}$ January 2015 . Due to the difference in size samples, the data collection at this site was extended to between $1^{\text {st } J a n u a r y ~} 2014-31^{\text {st }}$ March 2015 . The final number of patients identified to have undergone septoplasty was 41. Adjunctive turbinate surgery was performed in $92.7 \%$ of patients.

Using the combined data set, turbinate surgery was performed in $77.0 \%$. The mean patient age was 38.3 years (GH 37.3, JPUH 42.2 p=0.02). 27 different surgeons were identified, of which 11 were consultants or associate specialists. Three of the consultants were subspecialty rhinologists who performed adjunctive turbinate surgery in $65.9 \%, 56.4 \%$ and $81.8 \%$ of their patients respectively, giving an overall rate of $63.8 \%$, compared to $86.4 \%$ of non-rhinologists, of which $50 \%$ performed turbinate surgery in every case. Overall percentage of adjunctive

This article is protected by copyright. All rights reserved. 
turbinate surgery per grade of surgeon was as follows: Consultant (79.4\%), Associate Specialist/Staff grade (77.4\%), Specialist Registrar (75.7\%), Senior house officer (80\%).

Turbinate surgery was as follows: Turbinoplasty consisting of bony resection with mucosal preservation (32.3\%), Out-fracture (19.9\%), Coblation reduction (12.4\%), Submucosal diathermy (11.1\%), Resection and trimming (1.3\%), No turbinate surgery (23\%). The operating surgeon was strongly associated with both the decision to perform turbinate surgery $(\mathrm{p}<0.001)$ and the technique (ANOVA $\mathrm{p}<0.0001$ ), indicating that when choosing to perform a turbinate procedure, each surgeon had a clearly preferred technique in the majority of their cases. The sex and age of the patient did not influence technique choice.

Twenty-eight patients had preoperative RAST or skin-prick testing (12.4\%) and 15 out of 28 $(53.6 \%)$ had elevated IgE levels on RAST testing or a positive allergen on skin-prick testing; 69.2\% of RAST/skin-prick negative patients and 93.3\% RAST/skin-prick positive patients underwent turbinate reduction. Twenty asthmatic patients were identified within the Guy's Hospital data series (10.8\%), and 18 of the asthmatics (90\%) underwent turbinate reduction.

\section{Discussion}

\section{Synopsis of key findings}

This study has shown that adjunctive turbinate surgery is commonly being performed alongside septoplasty for nasal obstruction, using a variety of methods. There is little evidence in the literature to inform surgeons on the comparative effectiveness of different methods of turbinate reduction. Published studies are small, often non-randomised and at high risk of bias, and usually compare only two different methods to each other. The variety of indications and disease processes are not compared, resulting in no current gold standard. A contributing factor could be that the effectiveness of either septoplasty or turbinate reduction is also difficult to assess given how they are often performed as paired procedures and therefore more studies are required to further differentiate their individual or paired operative value.

Furthermore there is no randomised evidence comparing adjunctive turbinate surgery to no turbinate surgery. The American Academy of Otolaryngology-Head and Neck Surgery consensus statement on septoplasty with or without inferior turbinate reduction showed panel consensus that inferior turbinoplasty is an effective adjunctive procedure to septoplasty in the presence of hypertropic inferior turbinates (6). A recent retrospective cohort study has suggested that concomitant inferior turbinate surgery may decrease the need for revision procedures at a later date. In a series of 2168 cases, the incidence of revision surgery was $5.1 \%$ in those who underwent septoplasty alone compared with $2.2 \%$ in those who underwent concomitant inferior turbinate reduction (7).

This article is protected by copyright. All rights reserved. 
It is interesting that both the decision on whether to perform turbinate surgery and the chosen technique for turbinate reduction was statistically strongly associated with the surgeon performing the procedure. There was some selection at individual patient level, as patients with positive skin-prick test results and asthma were more likely to have turbinate surgery. However, it may also suggest that causative pathology is not always considered in each individual patient, and turbinate reduction is being performed regardless of presence or lack of causative pathologies. Nearly $50 \%$ of surgeons performed turbinate reduction in some form in all of their septoplasty patients, using conservative techniques such as outfracture or submucosal diathermy. The lowest rates of turbinate surgery were performed by rhinologists, however where surgery was performed, they were more likely to use turbinoplasty. Turbinoplasty involves removal of the anterior turbinate bone and lateral mucosa, using either cold steel or powered instrumentation. This forms a neoturbinate using the retained medial mucosa, preserving function, reducing the exposure of denuded bone and hence crusting postoperatively, and achieves a better lasting control of turbinate hypertrophy (8).

\section{Strengths of the study}

This study captures current practice in the hands of a wide range of surgeons, demonstrating wide variation in practice. Our results suggest that more evidence is required regarding the role of adjunctive turbinate surgery, and the current literature base is sparse in evidence regarding selection and effectiveness.

\section{Limitations}

This study does not address the outcomes of the surgery, as the study was designed to consider indications for surgery, not effectiveness. The study was performed retrospectively and therefore only the information documented was able to be considered. As turbinate size was not known, it is alluded to that surgeon preference was the major influencing factor, however a prospective study would be required to fully assess other influencing factors and their full impact. There may also have been further influencing factors for turbinate reduction method choice, for example coagulopathy or pre-operative turbinate size, which may have not been captured. Data collected did not reflect any pre-operative turbinate vasoconstrictor tests, although this was felt to not be a test commonly applied within the institutions when listing for septoplasty with or without inferior turbinate reduction. Further studies would be required to assess whether there was a place for this in adjunctive turbinate reduction in regards to septoplasty, and the methods used. This study reflects the practice in two institutions and whilst it raises concerns about turbinate surgery indication within them, further multi-centre studies would have to be performed to clarify whether this was representative of the specialty as a whole.

\section{Clinical applicability of the study}

With an apparent lack of consideration for causative pathology, patients may be undergoing adjunctive turbinate surgery unnecessarily and thereby could be being exposed to potential morbidity. Early complications include infection and bleeding, crusting, adhesions, and long-

This article is protected by copyright. All rights reserved. 
term complications of loss of turbinate function (empty nose syndrome), can occur (9). This can in turn be associated with further surgical procedures, and also increases the overall cost to the health service both for the initial procedure treatment of resulting morbidity. Conversely, if patients having adjunctive turbinate surgery achieve better results, some patients may be missing out on this.

\section{Key points}

1 Septal and turbinate surgeries are often performed concurrently for nasal obstruction

2 Causative pathology for each structure leading to symptoms can be divided into structural and mucosal

3 The decision to perform both procedures simultaneously should be at an individual patient level

4 Turbinate reduction was statistically strongly associated with which surgeon is performing the procedure

5 Effectiveness of either septoplasty or turbinate reduction is difficult to assess given how they are often performed as paired procedures and therefore more studies are required to further differentiate their individual or paired operative value.

\section{References}

$1 \quad$ Gray LP. Deviated nasal septum. Incidence and aetiology. Ann Otol Rhinol Laryngol Suppl. 1978 May-Jun;87(3 Pt 3 Suppl 50):3-20

2 Farmer SE, Eccles R. Chronic inferior turbinate enlargement and the implications for surgical intervention. Rhinology 2006; 44:234-238

3 Willatt D. The evidence for reducing inferior turbinates. Rhinology 2009; 47:227-236

This article is protected by copyright. All rights reserved. 
$4 \quad$ Batra P, Seiden A, Smith T. Surgical management of adult inferior turbinate hypertrophy: A systematic review of the evidence. Laryngoscope 2009;119:1819-1827

5 Clement WA. White PS. Trends in turbinate surgery literature: A 35-year review. Clin Otolarygol Allied Sci 2001; 26:124-128

6 Han JK et al. Clinical consensus statement: Septoplasty with or without inferior turbinate reduction. Otolaryngol Head Neck Surg. 2015 Nov;153(5):708-20

7 Karlsson TR, Shakeel M, Supriya M, Ram B, Ah-See KW. Septoplasty with concomitant inferior turbinate reduction reduces the need for revision procedure. Rhinology 2015;53:59-65

8 Barham HP et al. Long-term outcomes in medial flap inferior turbinoplasty are superior to submucosal electrocautery and submucosal powered turbinate reduction. Int Forum Allergy Rhinol 2015 Dec 17. doi: 10.1002/alr.21574. [Epub ahead of print]

9 Philpott C, Banerjee A. Is there a role for more day-case septal surgery? J Laryngol Otol. 2005 Apr;119(4):280-3

\section{Conflicts of Interest}

Miss Claire Hopkins and Mr Carl Philpott have jointly submitted a bid for the 'Septoplasty for a deviated nasal septum' National Institute for Health Research (NIHR) randomised control trial

This article is protected by copyright. All rights reserved. 